\title{
THE USE OF PHYSICS POCKETBOOK BASED ON AUGMENTED REALITY ON PLANETARY MOTION TO IMPROVE STUDENTS' LEARNING ACHIEVEMENT
}

\author{
Nadi Suprapto $^{1}$ (D), Handal Setyo Ibisono ${ }^{1}$ (D), Husni Mubarok ${ }^{2}$ iD \\ ${ }^{1}$ Universitas Negeri Surabaya (Indonesia) \\ ${ }^{2}$ National Taiwan University of Science and Technology (Taiwan) \\ nadisuprapto@unesa.ac.id, handalibisono@gmail.com,busnimubarok254@gmail.com
}

Received November 2020

Accepted June 2021

\section{Abstract}

Planetary motion in physics learning is an abstract concept and requires high reasoning. This article is one of the augmented realities (AR)-based pocketbook development on the planetary motion, focusing on student learning achievement. The study used the ADDIE model: "Analysis-Design-Development-Implementation-Evaluation". In the Spring Semester 2020, researchers took these steps in producing an AR-based pocketbook on planetary motion materials. The trial carried out on 30 students (57\% girls and 43\% boys, with age 16-17) at a public high school in Surabaya, Indonesia. Evaluation parameters included the quality of the AR-based pocketbook, students' learning achievement, and research outputs. Data analysis techniques used descriptive statistics, N-gain score, and independent t-test. The results showed that: (1) the process of developing an AR-based pocketbook on planetary motion fulfilled the product quality criteria: validity, practicality, and effectiveness; (2) students' learning achievement increase as seen from the results of the pretest-posttest scores with the average Gain score was 0.63 in the moderate category in which the boys perform better than the girls; (3) through the development of an AR-based pocketbook, it resulted in some articles in journals and pocketbook media based on Augmented reality. Therefore, this study's recommendation is to use AR as a media for learning in other abstract physics concepts.

Keywords - Student learning achievements, Augmented reality, Physics, Planetary motion.

\section{To cite this article:}

Suprapto, N., Ibisono, H.S., \& Mubarok, H. (2021). The use of physics pocketbook based on augmented reality on planetary motion to improve students' learning achievement. Journal of Technology and Science Education, 11(2), 526-540. https://doi.org/10.3926/jotse.1167

\section{Introduction}

The direction of technological development has again entered the education field, such as the classroom's learning process. This technological development has presented several online learning materials in science and other areas that involve "learning in various contexts through social interaction and content using personal electronic devices" (Crompton, 2013). One of the personal electronic devices as a learning media in the classroom is augmented reality technology. The focus of this research is physics learning media assisted by augmented reality. 
It is not easy to perform an abstract concept in the classroom. In other words, this is a challenge for educators worldwide to develop learning media to make it easier to explain the material, especially in learning fields that require a reasonably high understanding like physics content. In physics, students are trained to think to study a phenomenon logically and mathematically. Students are expected to have an excellent conceptual understanding so that learning physics objectives can be adequately achieved (Gunawan, Nisrina, Suranti, Herayanti \& Rahmatiah, 2018). In physics learning, understanding the concepts in every physics context is required (Husnaini \& Chen, 2019; Suprapto, Nandyansah \& Mubarok, 2020). Therefore, the method of delivering the teacher's material is very influential in shaping the students' concepts of physics lessons (Adam \& Suprapto, 2019). One of the technologies in the multimedia field, which developing and can make it easier to explain the concept of physics is Augmented Reality (AR) (Abdusselam \& Karal, 2020; Bakri, Permana, Wulandari \& Muliyati, 2020; López-Belmonte, Pozo-Sánchez, Fuentes-Cabrera \& Romero-Rodríguez, 2020; Nandyansah, Suprapto \& Mubarok, 2020).

AR is a technology capable of realizing objects in the virtual world into the real world and converting $2 \mathrm{D}$ objects into 3D objects (Arslan, Kofoğlu \& Dargut, 2020; Permana, Tolle, Utaminingrum \& Dermawi, 2019). Kustijono and Hakim (2014) stated that AR was an attempt to combine the real world and the virtual world created employing a computer so that the boundary between the two becomes very thin. The AR application can make 2D animated objects into 3D animation so that these objects become real. AR technology can be used to design a concept of information from paper-based to be video. The system built was able to recognize markers and display videos that were loaded via URL (Marneanu, Ebner \& Rößler, 2014; Sing, Ibrahim, Weng, Hamzah \& Yung, 2020). Therefore, this technology needs printed media, such as pocketbooks, as support.

Some previous researches concerned with the use of augmented reality in various existing methodological approaches in the teaching of physics, such as problem-based learning (Fidan \& Tuncel, 2019), inquiry-based learning (Radu \& Schneider, 2019), and teaching with interactive books (Dünser, Walker, Horner \& Bentall, 2012). However, this study focuses on the use of AR in the teaching of physics abstract concept.

In the education field, AR can attract, motivate, and provide real visuals for someone in understanding a material that requires high enough reasoning and imagination in understanding a material concept (Lee, 2012). Therefore, objects in learning that have only been imagined or only listed on printed media in $2 \mathrm{D}$ can be realized using AR to improve student learning outcomes (Chen \& Wang, 2015). AR was developed to use several supporting applications in its manufacture, such as a 3D blender, which helps create 3D objects; vuphoria helps make markers to be used, and unity for combining 3D animation with markers has been made.

The AR output can be installed directly on an Android smartphone (Marneanu et al., 2014). The operation of the AR media application is straightforward; when opening the AR application, it will appear on the smartphone camera, which can be directed directly at the supporting pocketbook, and a marker is available that will be detected by the application so that 3D animated objects will appear on the smartphone screen. As shown in Figure 1, is a mechanism to operate the AR application.

One way to obtain a comprehensive literature review is to close the findings of previous research by checking the relevant previous empirical publications to obtain the development of a treasure trove of related knowledge, especially about augmented reality. Through Figures 2 to 4 , the authors try to give a whole picture of how previous researchers concern with AR. Figure 2 depicts the research trends of augmented reality based on the Scopus database from the beginning until 2020 as preliminary research conducted by the authors. The data was recorded on 30 September 2020. There are five significant clusters on the research of AR: the use of a quantitative method in dealing with AR (yellow color), the technology behind AR application (purple color), the process of developing AR including validity and strategy (red color), a systematic review on AR (blue color), AR and virtual environment (green color). 


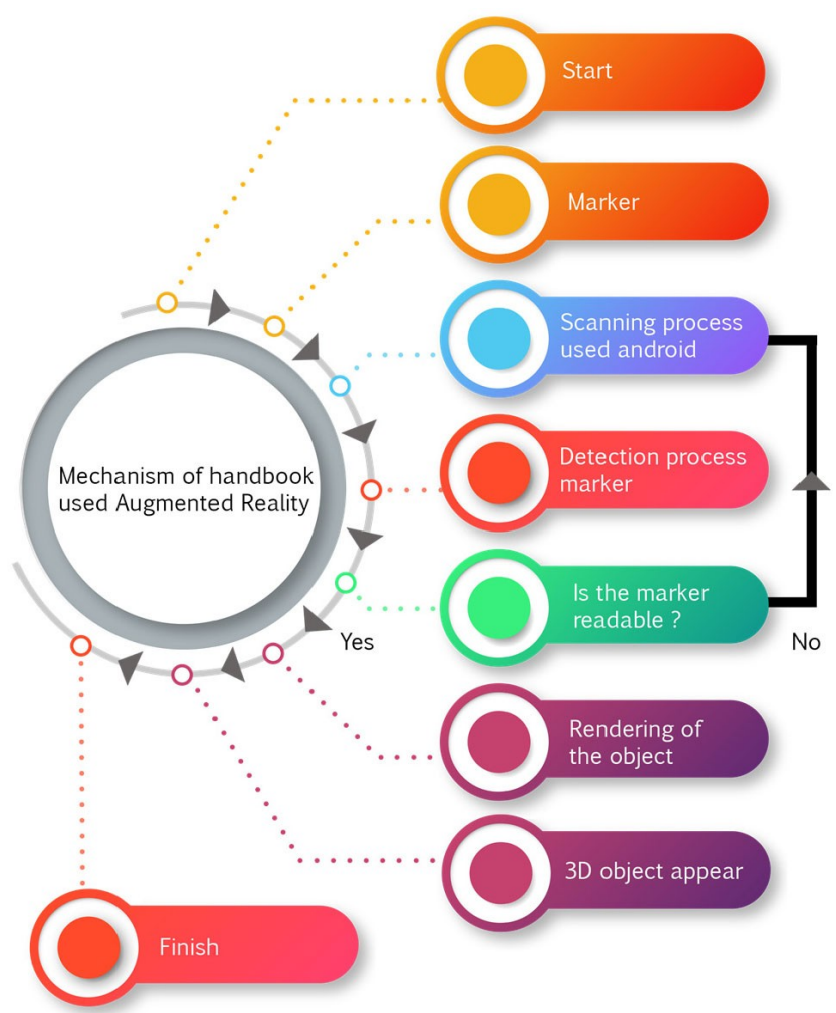

Figure 1. Mechanism of handbook used augmented reality

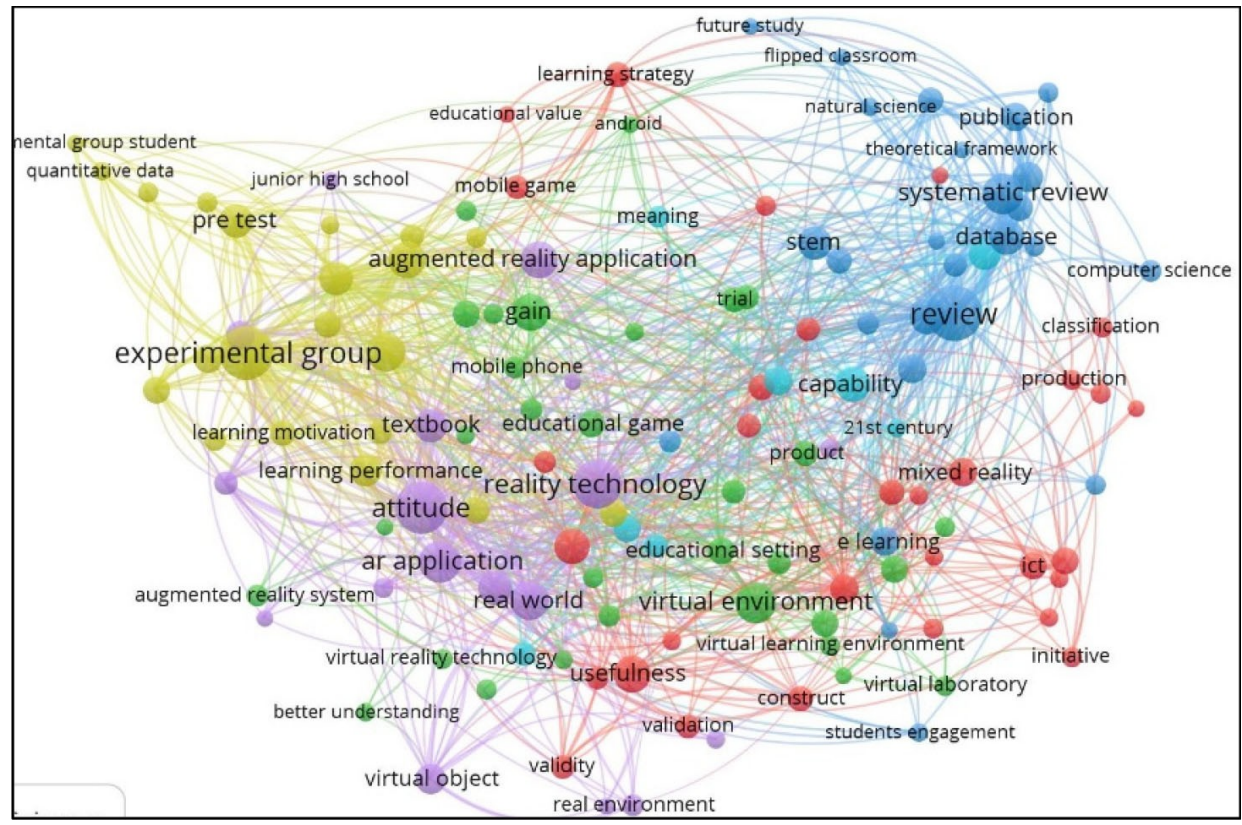

Figure 2. Research trends on augmented reality based on Scopus database

Meanwhile, Figure 3 is specifically on how AR relates to academic achievement. It was clear that many researchers explore how the use of AR in predicting academic achievement (see Ibáñez, Portillo, Cabada \& Barrón, 2019; Sirakaya \& Cakmak, 2018). Therefore, this study that uses a physics pocketbook based on AR on the planetary motion improves students' learning achievement. It is still in the research area of researchers in the world. 


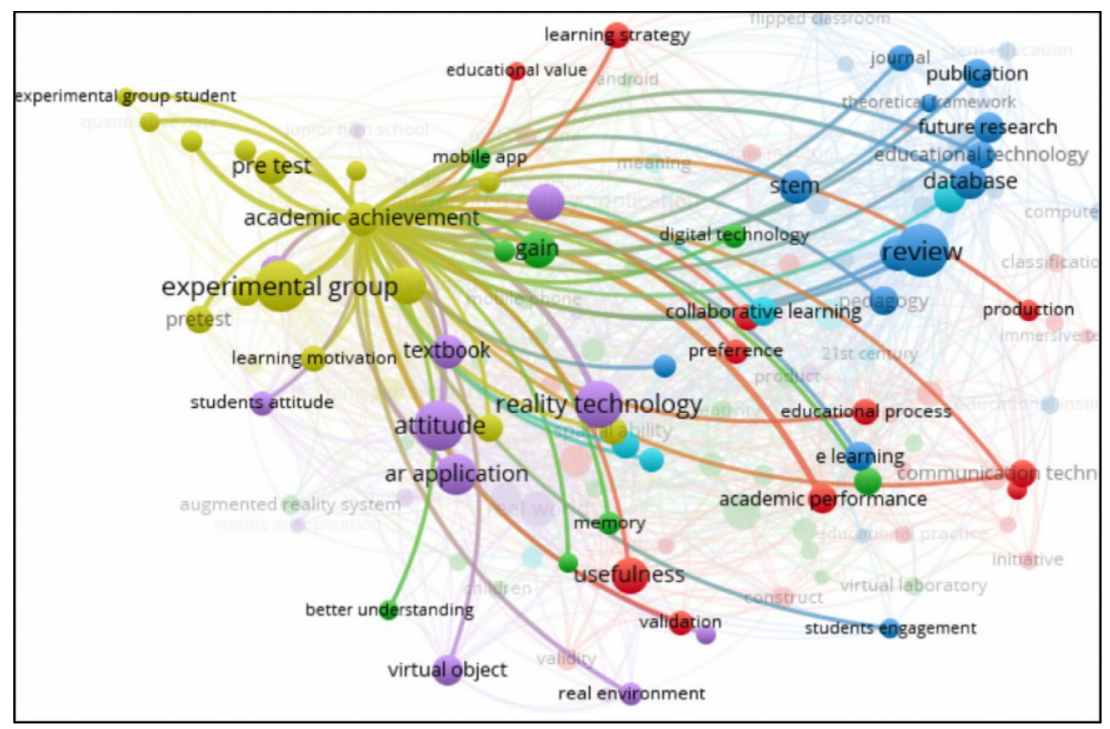

Figure 3. AR in relating to academic achievement

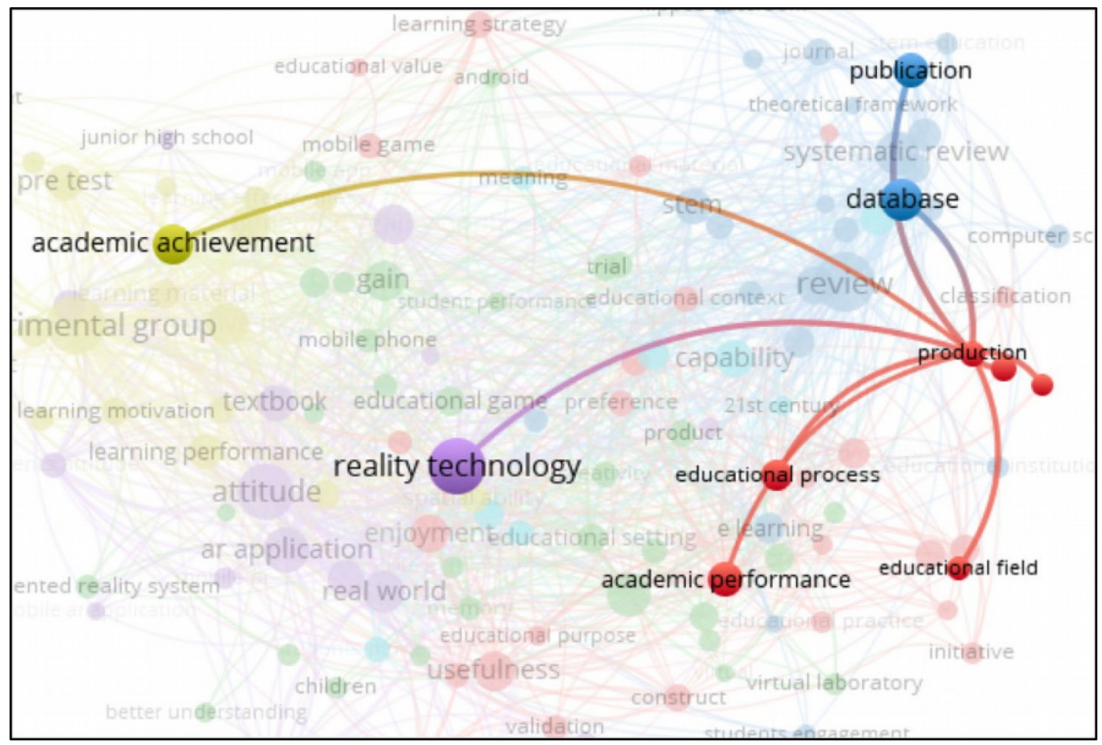

Figure 4. AR in relating to production process

On the other hand, Figure 4 illustrates the production process of AR. It means many researchers still focus on developing some aspects of AR, including validity, practicality, and effectivity. In line with this research, it begins with developing a pocketbook for physics concepts assisted by AR technology. So that through this development, research will enrich the scientific treasures related to the development of pocketbooks with AR technology in the field of study. Figure 4 also clearly shows how AR technology's development or production is closely related to student achievement. Figures 2 to 4 supported the idea of this research that considers the use of AR in improving students' learning achievement.

The augmented reality-based pocketbook was developed to facilitate students to more easily understand abstract material concepts and require much imagination, such as the concept of learning physics on planetary motion material. The main research questions in the development of this research were (1) Does the pocketbook based on augmented reality on planetary motion material meet the product quality criteria (validity, practicality, and effectiveness)? (2) To what extent do the performance of pocketbook base on augmented reality in planet motion? (3) To what extent do student achievement results after participating in learning using a pocketbook based on augmented reality? These three main questions are the explanation of the evaluation parameters that refer to this research. 


\section{Method}

This study used an ADDIE model in designing a learning system (Adam \& Suprapto, 2019). The ADDIE is an abbreviation from "Analyze, Design, Development, Implementation, and Evaluation". The advantage of the ADDIE model is a systematic work procedure. Each step always refers to the previous step that has been corrected to obtain an effective product. Visually, the ADDIE model stages can be seen in Figure 5.

This research aimed to analyze, design, development, implement and evaluate the physics pocketbook based on augmented reality. In the analysis stage, the authors analyzed instructional media's needs through interviews and questionnaires given to teachers and students. In the design stage, the authors made a design or media design prototype. In the development stage, the authors realized a prototype in a pocketbook and an AR application with the Android operating system. Then perform the validation test by material and media experts.

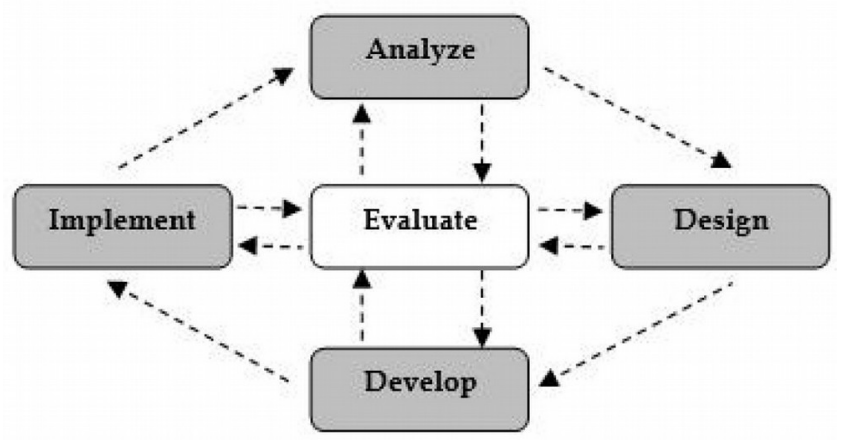

Figure 5. ADDIE development model scheme

In the implementation stage, this study developed a pocketbook based on AR as a learning media for physics with Android support for planetary motion. The authors need six months to develop the application. The steps in developing AR are as follows:

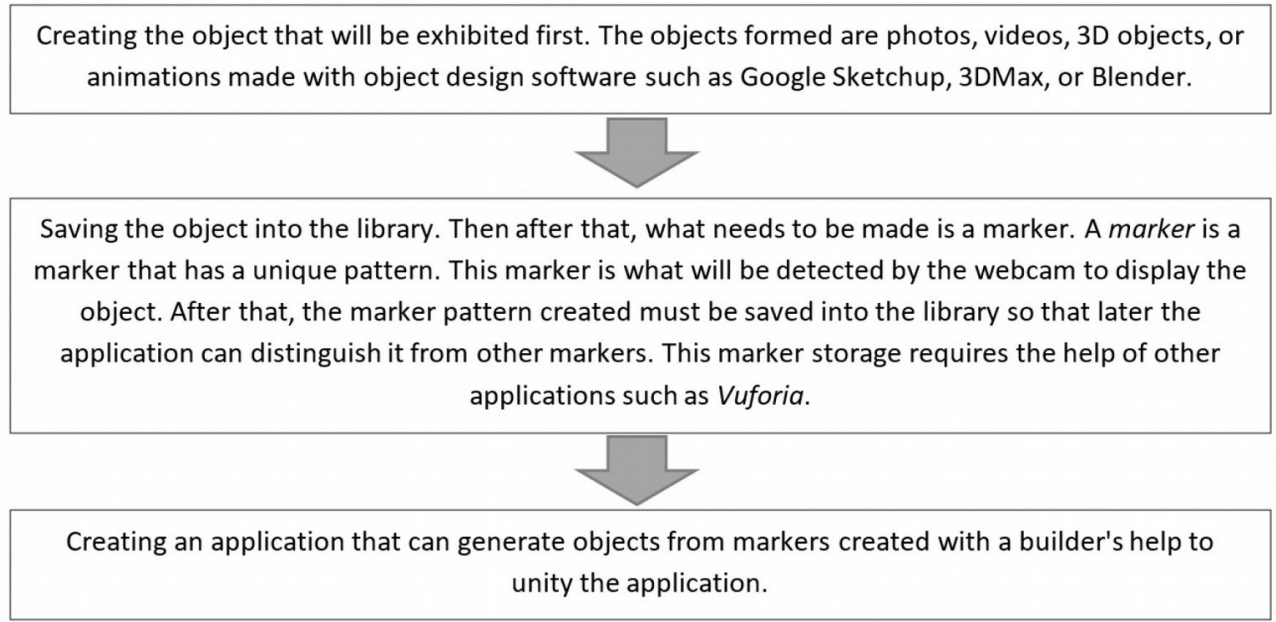

Figure 6. The specific steps in developing AR (Suprapto \& Nandyansah, 2021) 


\subsection{The Development Process of Pocketbook Based Augmented Reality}

Based on the method's explanation, research on the development of the pocketbook based on Augmented Reality to improve student learning achievement has been carried out using the ADDIE research design (Analysis, Design, Development, Implementation, and Evaluation). The following is an explanation of the stages of developing an Augmented Reality-based pocketbook.

Analysis: it was the stage to see any differences or gaps between the desired development of an academic world and the existing reality. The hope is that in the world of education, they should have used technology, especially AR media, to facilitate teachers to explain abstract concepts and help students understand conceptual material better. The use of technology, especially AR media, was still rarely applied by an educator or students in education. Even AR technology in the physics field of planetary motion material yet did not exist. This statement was supported by the results of a questionnaire conducted on 30 students. As many as $40 \%$ responded to the frequency of using the application of learning media in learning physics, the use of technology, including AR, has never been done in learning and physics material, especially on the planetary motion was still abstract and challenging to understand.

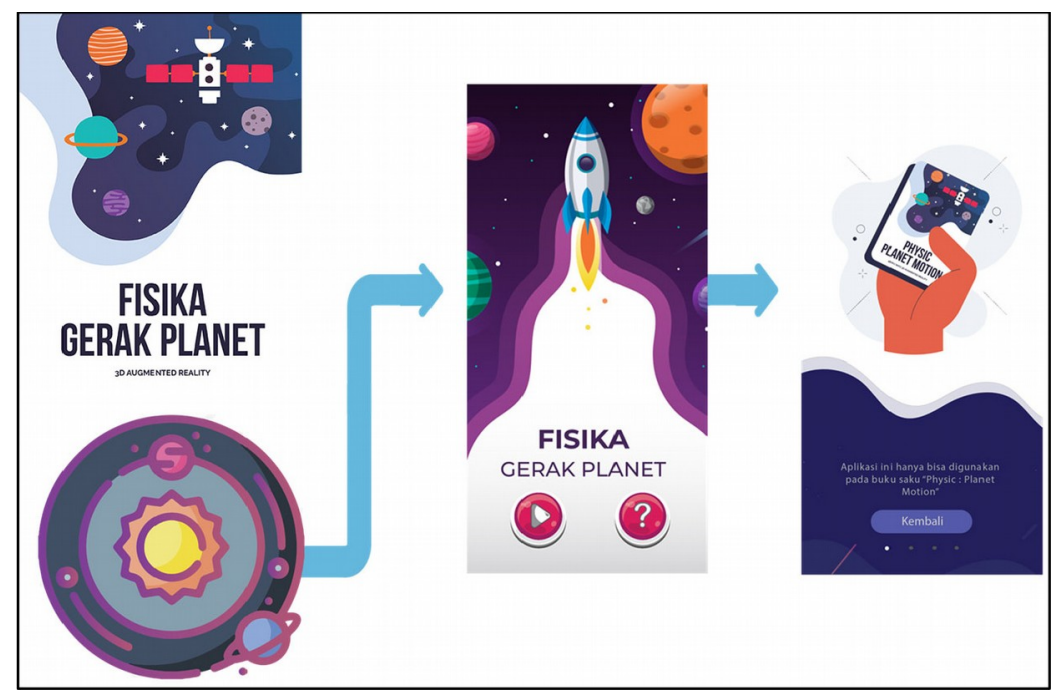

Figure 7. Interface design of augmented reality

Design: Before creating a pocketbook and AR application, the researchers made a media design based on the results of the analysis. The next step, the researchers started to made pocketbooks and AR applications that had been approved and in the seminar. The following was one of the designs created by the researchers, presented in Figure 7.

Development: At this stage, the media has been completed, the researchers conducted the validation stage of the AR-based pocketbook media and learning tools to two lecturers and one physics teacher before the media was realized in the learning process.

Implementation: At the implementation stage during the Covid-19 pandemic, an AR-based pocketbook was applied to online learning planet motion material to 30 students who were observed by school teachers and two assistants (student-teachers) from the University in Surabaya using observation sheets used to analyze the practicality of the media. Before students took part in learning using AR-based pocketbook media, a pretest was carried out first, after students participated in the learning, a posttest was carried out where the results of the pretest and posttest were used to see the increase in student learning performance which was analyzed using the Gain score. 
Evaluation: The results of the evaluation phase was used to determine the effectiveness of AR-based media. Based on Hake's statement, if the Gain score results obtained were $\geq 0.3$ (see Hake, 1998 in the moderate category, then the media was declared effective in improving student learning achievement.

The targets in this study were 30 students in grade ten age 16-17. The distribution of the students are $57 \%$ girls and $43 \%$ boys with all students with medium in socioeconomic status (SES). The research design used in this study was a one-group pretest-posttest design. Thus, there is only one group and no control group in this study. The treatment of the research included a pretest at the beginning and a posttest at the end of the lesson. The method of the tests carried out through the pretest and posttest was to determine the increase in student learning achievement. The normality test with a significance level of $5 \%$ on the pretest and posttest results to determine the data obtained was normally distributed.

After the pretest and posttest results were obtained, the results were analyzed using Gain score analysis with the formula presented in Equation 1 (Hake, 1998; Wang \& Chyi-in, 2004; Wayne \& Youngs, 2003). Meanwhile, the mean difference across gender was analyzed using an independent t-test.

$$
g=\frac{S r-S i}{S \max -S i}
$$

Note:

$g \quad=$ gain score

Sr $\quad=$ posttest score

Si $\quad=$ pretest score

Smax $=$ maximum score

\begin{tabular}{|c|c|}
\hline Gain score interval & Criteria \\
\hline$g>0.7$ & High \\
\hline $0.3 \leq g \leq 0.7$ & Moderate \\
\hline$g<0.3$ & Low \\
\hline
\end{tabular}

Table 1. Criteria of Gain score (Hake, 1998)

Based on Table 1, the Gain score interpretation criteria, the AR-based pocketbook was declared effective if the results of the students' pretest and posttest after being analyzed using Gain score get a range of $\geq 0.3$ in the medium to high category.

\section{Results and Discussion}

\subsection{The Performance of Pocketbook based Augmented Reality in Planet Motion}

On the topic listed in the pocketbook based on AR about planetary motion, it can be analogized if the planets move around the sun in a trajectory approaching a circle. All planets and other celestial bodies, including the earth, move according to their trajectory (orbit) around the sun (Mubarok \& Aliyah, 2019). Of course, there is a force holding these objects towards the center of their path. To explain this phenomenon, Newton proposed the theory of universal gravity. Universal means that it applies to all objects in the universe. Every object in the universe exerts an attraction force (Serway, 2018). In physics, the order of the universe can be explained based on Kepler's laws and Newton's laws of gravity.

Explanation of Kepler's Law using a pocketbook media based on AR: Johannes Kepler was an astronomer and mathematician who investigates planetary motion. In the solar system, Kepler found that the planets move with speed is not constant, but move faster when close to the sun than when far from the Sun (Serway, 2018). Using precise mathematical relationships between the periods of the planets and the average distance from the sun, Kepler was able to conclude in the laws of planetary motion, which became known as Kepler's laws. 


\subsubsection{Kepler's First Law}

Kepler's first law states that all planets move in elliptical orbits with the Sun as one focus (Serway, 2018).

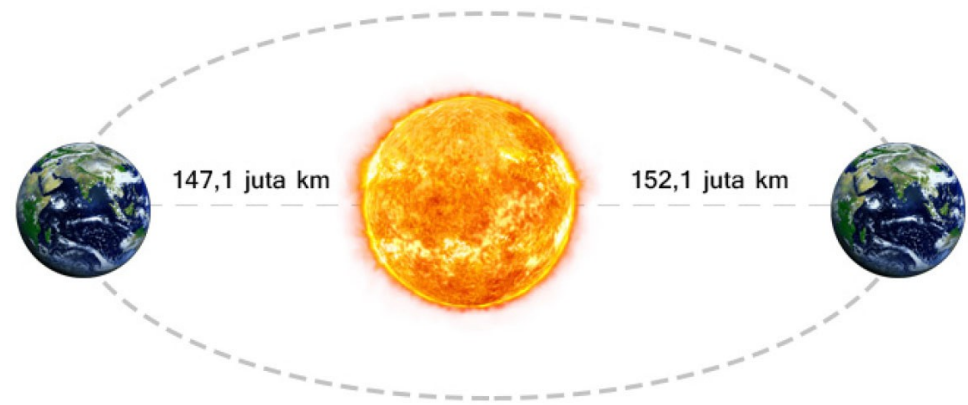

Figure 8. The elliptical trajectory of the planet

Figure 8 shows the elliptical trajectory of the planet with the Sun at one of its focal points. The point of the Earth-orbiting the Sun is the average distance between the Sun and the Earth. The point where the planet is closest to the Sun is called Perihelion. At the same time, the planet's farthest point from the Sun is called Aphelion. In the pocketbook based on 2D visual augmented reality referred to in Kepler's first law, it will be easier to understand, because the image object will be projected as in the image below. The following is a display of 3D objects in Augmented reality regarding the explanation of Kepler's first law.

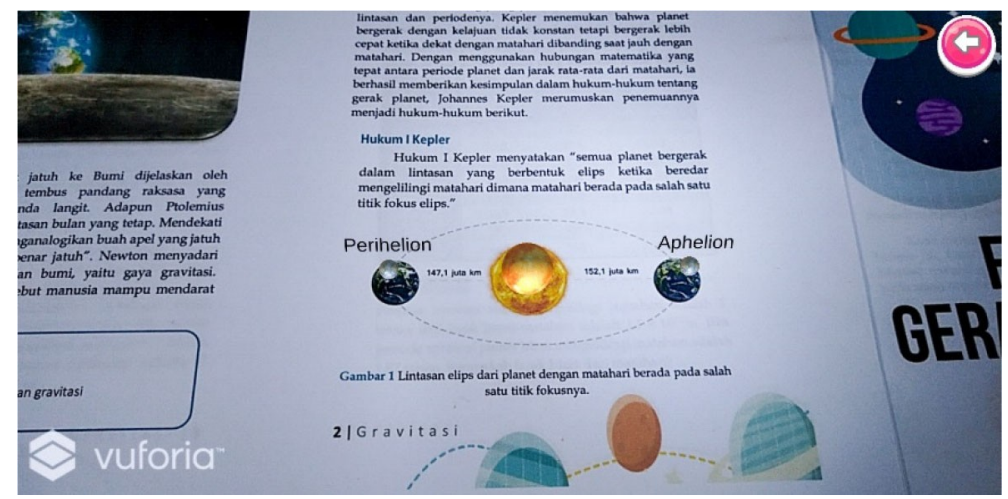

Figure 9. Projection of planetary trajectory 3D objects

\subsubsection{Kepler's Second Law}

Kepler's Second Law states that each planet moves in such a way that an imaginary line drawn from the Sun to the planet covers an area of the equal area at the same time (Prakoso, Adityas, Nurhaqi \& Setianto, 2019). The following is a 2D image of Kepler's Second Law which would be visualized in 3D with AR.

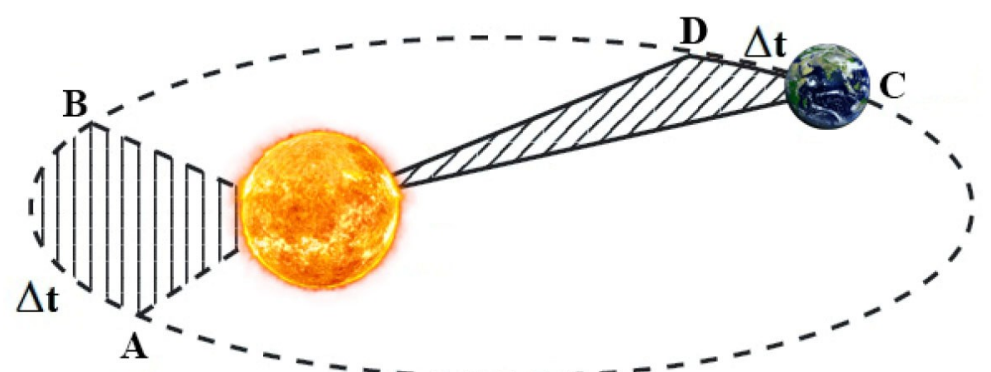

Figure 10. All landscaped areas have the same area values at the same time 
From Figure 10, this display can be visualized in 3D or as real with an AR-based pocketbook shown in Figure 11. So that students can understand the concepts in Kepler's Second Law.

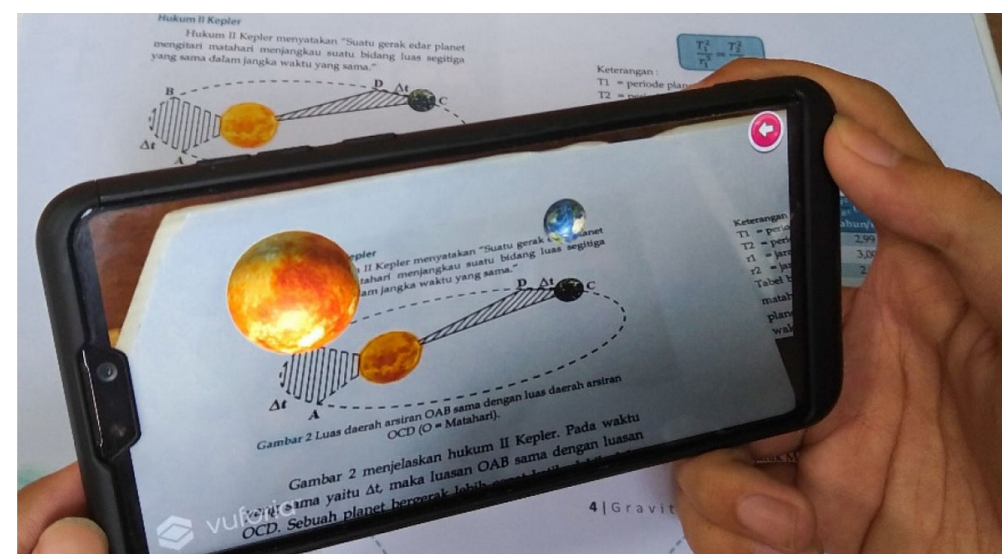

Figure 11. Kepler's second law 3D object projection

Explanation of gravitational force using AR-based pocketbook media: Furthermore, unlike Kepler, who only saw the symptoms of the orbits of planets on the trajectories of each planet, Newton could see that there was a robust relationship between the orbits of the planets and their mass, planet itself. Even Newton dared to conclude that the orbits of the planets are influenced by force called gravity, whose value is greatly influenced by the mass of the planets themselves (Halliday, Resnick \& Walker, 2013). Here is Newton's law of gravity. "Every two objects in the universe will attract each other with a force that is proportional to the mass of each object, and inversely proportional to the square of the distance".

In determining a gravitational force, it is necessary to have a mathematical explanation so that the equation for the law of gravity is fulfilled, but in this formula, the value of the gravitational constant $(G)$ is not yet known. Therefore, Henry Cavendish conducted an experiment using two solid balls of known mass. The two balls are hung to avoid as little friction as possible. From the results of a cautious experiment, the two balls will produce an attractive force and cause the positions of the two solid balls to shift to find the gravitational constant. Figure 12 indicates Henry Cavendish's experiment.

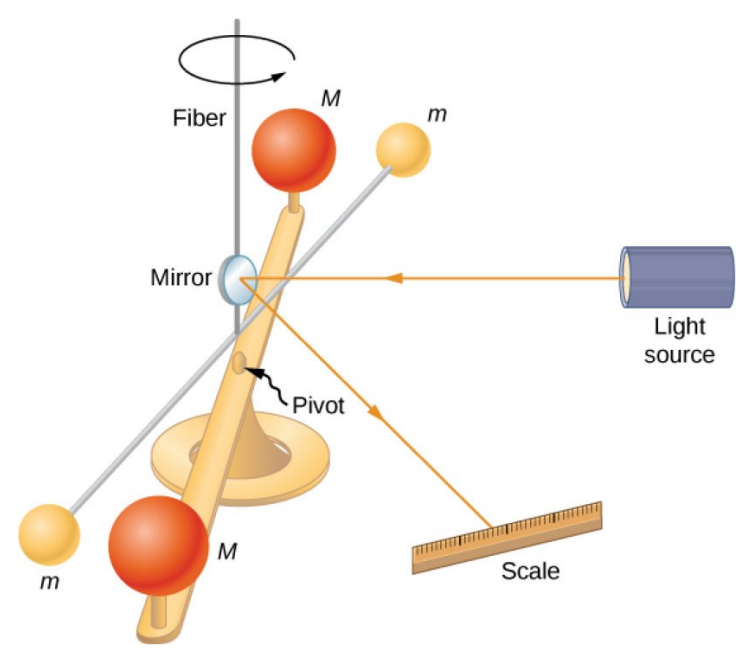

Figure 12. Cavendish Balance Scheme (Samuel, Sanny \& Moebs, 2018)

Not everyone can imagine or see firsthand the experimental tools that Henry Cavendish used to find this gravity constant. Therefore, this AR-based pocketbook presents a real visual of the experimental tool. Figure 13 represents Henry Cavendish's experimental tool with AR. 


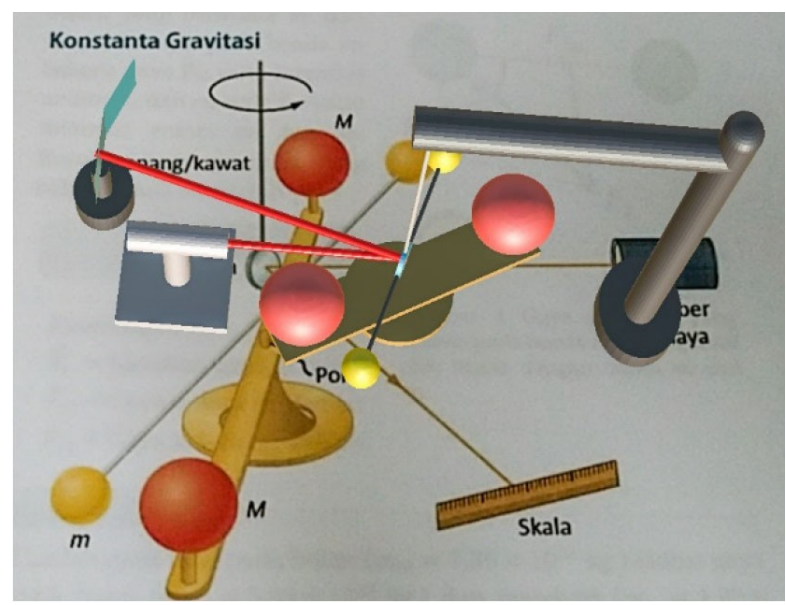

Figure 13. The projection of Cavendish balance schematic 3D object

\subsection{The Performance of the Students' Achievement}

The main target of using an AR-based pocketbook in physics learning was to improve student learning achievement. Students' learning performance will be seen through the pretest and posttest scores which were then analyzed using the Gain score to see a significant improvement. The AR-based pocketbook will be declared effective in the Gain score criteria if the results of the Gain score analysis score $\geq 0.3$ with reasonable minimum standards (Hake, 1998). The pretest and posttest questions were in the form of multiple-choice with the same questions. The contents of the test include planetary motion material that has been presented in the AR table. The test will be given to the same 30 students. The learning achievement of students, as seen from the results of the pretest and posttest, can be seen in Figure 14.

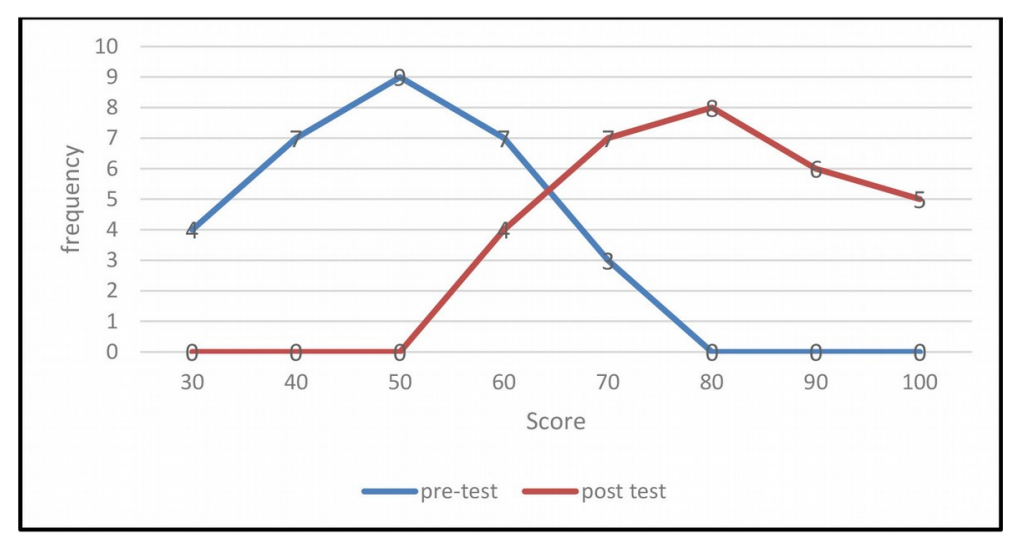

Figure 14. The result of pretest and posttest

Figure 14 shows the pretest and posttest results on students who have followed learning using an AR-based pocketbook. Before conducting the test, students are given a minimum score that must be achieved as a reference in assessing the minimum score. The score that these students must complete is 70. Based on Figure 14, it can be seen from the 30 students who took the test, 27 students got pretest scores for planetary motion material below the minimum score, or the score was below 70. In comparison, the other three students have scored above the minimum. The number of students who still get scores below the minimum during the pretest was because they have not been given learning planetary motion using AR media, so to answer the test questions, students still use general knowledge.

Based on Figure 14 above, it can also be seen that the posttest results of students after being given learning material on planetary motion using a pocketbook based on AR media, these results show better results than the results in the pretest. It can be seen that as many as 26 students scored above the minimum score, which means that they had exceeded the value of 70 , but there were four students whose 
scores had not exceeded the minimum score. Students who get posttest scores above the minimum score were more than those who get scores below the minimum; this happens after learning occurs using an AR-based pocketbook. This AR-based pocketbook could present visuals that make students feel as if they were faced with a genuine learning object. Therefore, the teaching and learning process was more fun and easier to understand the subject matter (Suprapto et al., 2020), for example, as the orbit of the earth's trajectory around the sun in the form of an ellipse will be presented clearly with 3D visuals so that students can more easily understand this concept. This case was also supported by Nandyansah et al. (2020) research that AR media was adequate for use in learning; students were able to more comprehensively in abstract thinking skills.

After participating in learning using the AR-based pocketbook, the increase of student learning achievement was also analyzed using the Gain score. Each student's value in Figure 15 has been tested using the Kolmogorov-Smirnov normality test and obtained a pretest normality result of 0.062 and a posttest of 0.069 , which shows that the data has been customarily distributed and fulfils the requirements for Gain score analysis. The results of the students' Gain score analysis can be seen in the following Figure 15.

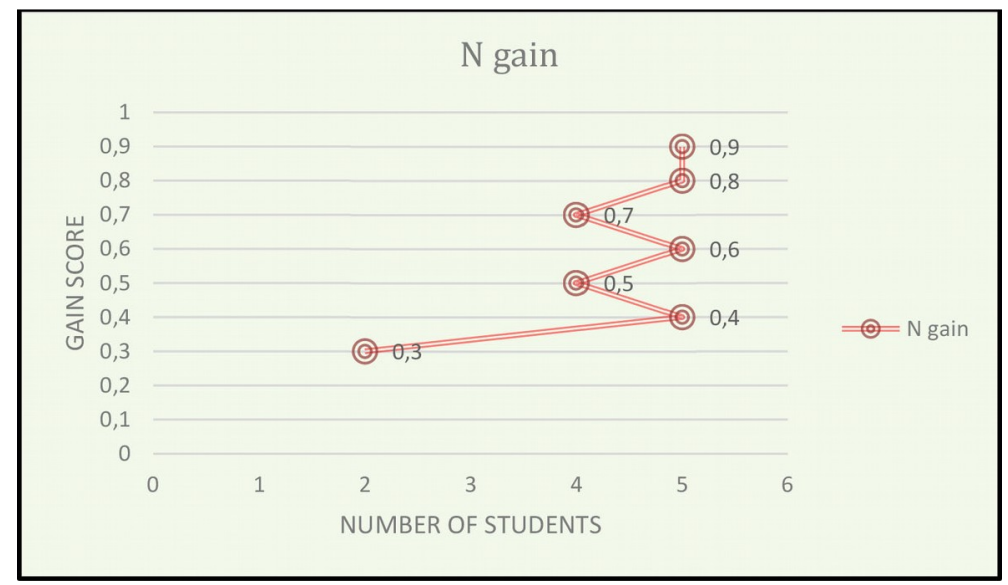

Figure 15. Gain score of students

Figure 15 shows as many as 16 students in the medium category and 14 students in the high category according to Hake's criteria (1998). It means the use of AR impacts students' achievement (Wang \& Chyi-In, 2004; Wayne \& Youngs, 2003). These results were obtained after students took part in learning using an AR-based pocketbook and experienced an increase. Some students who share an increase in learning achievement with this high category were because, in this AR-based pocketbook, they can visualize the form of images in planetary motion material into 3D visuals that students can observe. This $3 \mathrm{D}$ visual could make it easier for students to understand and see the details of shapes or images. The material can enter their long-term memory; this was also reinforced by Aljojo, Munshi, Zainol, Al-Amri, Al-Aqeel, Al-khaldi et al. (2020) research, which states that AR media can improve the student imagination and learning process. This score was a significant value for improving student learning achievement; therefore, AR media was proven to improve learning achievement (Rohendi \& Wihardi, 2020).

\begin{tabular}{|l|r|r|c|}
\hline \multicolumn{1}{|c|}{ Students } & N & Gain score & Criteria \\
\hline Overall & 30 & 0.63 & Moderate \\
\hline Boys & 13 & 0.73 & High \\
\hline Girls & 17 & 0.55 & Moderate \\
\hline
\end{tabular}

Table 2. Gain score obtained between boys and girls 
It was also shown by the results of the students' average Gain score of 0.63 in the medium category. However, if we compare the gain score between boys and girls, there is a significant difference. The boys perform better than girls, with a gain score of 0.73 (high category) vs 0.55 (moderate category). Then, from the independent t-test results, there is a significant difference in achievement between boys and girls. The posttest score of boys more significantly greater than the girls (see Table 3). This result was in lined with the previous research such as Ahmad, Goldiez and Hancock (2005) and Hsu (2019), who underlined boys' dominance over girls in the use of technology such as AR. The pretest and posttest questions were given the same so that it could be seen a significant improvement. From the research results above, this AR-based pocketbook was practical to be applied and as a learning medium that helps students improve their learning achievement.

\begin{tabular}{|l|l|r|r|r|r|}
\hline & \multicolumn{1}{|c|}{ Gender } & N & \multicolumn{1}{c|}{ M } & \multicolumn{1}{c|}{ SD } & \multicolumn{1}{c|}{ SE } \\
\hline \multirow{2}{*}{ Student Achievement } & Boys & 13 & 90.00 & 5.774 & 1.601 \\
\cline { 2 - 6 } & Girls & 17 & 81.18 & 6.002 & 1.456 \\
\hline
\end{tabular}

\begin{tabular}{|l|l|r|r|r|r|r|}
\hline \multicolumn{2}{|c|}{} & \multicolumn{1}{c|}{ F } & \multicolumn{1}{c|}{ Sig. } & \multicolumn{1}{c|}{ t } & \multicolumn{1}{c|}{ df } & \multicolumn{1}{c|}{ Sig. (2-tailed) } \\
\hline \multirow{2}{*}{$\begin{array}{l}\text { Student } \\
\text { Achievement }\end{array}$} & Equal variances assumed & .426 & .519 & 4.055 & 28 & .000 \\
\cline { 2 - 7 } & Equal variances not assumed & & & 4.077 & 26.472 & .000 \\
\hline
\end{tabular}

Table 3. The results of independent t-test of t-test between boys and girls

\section{Discussion}

Research on the use of AR in teaching and learning have been used widely by some researchers. Research conducted by López-Belmonte et al. (2018) highlighted that younger teacher in Spain tend to implement methodologies based on the use of emerging mobile technologies such as AR. This study was also implemented by the younger teacher (second author), who optimized the emerging technologies in learning. Moreover, to activate the students' professional skills, Díaz-Noguera, Hervas-Gomez and Calle (2019) suggested AR as a solution. However, their participants consisted of students in multidiscipline. This study focused on physics learning. Study in a similar country, Indonesia, Bakri et al. (2020) integrated AR media in their student worksheet in which it was also provided videos related to the topic of practicum. On the other hand, this study specialized in using a physics pocketbook based on augmented reality.

This research gives an additional lens of teaching physics with interactive books as Dünser et al. (2012) study. It was also clear that how the use of AR success contributing to academic achievement. The study has also in-line with Ibáñez et al. (2019) and Sirakaya and Cakmak (2018). Therefore, it could be claimed that using a physics pocketbook based on AR on planetary motion improves students' learning achievement. The next point is the dominance of boys over academic achievement after implementing AR. This result is in-line with the previous research such as Ahmad et al. (2005) and Hsu (2019), who underlined boys' dominance over girls in the use of technology such as AR.

\section{Conclusion}

Based on the research questions and the results of this research, the conclusion derived were:

1. The process of developing a pocketbook based on Augmented reality on planetary motion material fulfils the product quality criteria based on validity, practicality and effectiveness.

2. The performance of pocketbook base on augmented reality in planet motion could be explored from its step: analysis, design, development, implementation, and evaluation and the features were performance. 
3. Student learning achievement was increase after participating in learning using pocketbook based on augmented reality. It was seen from the results of the pretest-posttest scores, and analyzed using Gain score analysis, get an average of 0.63 in the moderate category. The boys perform better in academic achievement compare to the girls after implementing a pocketbook based on AR.

Indeed, through the development of AR-based pocketbook, it has resulted some publications in relevant journals, AR-based pocketbook media, and property rights.

\section{Acknowledgement}

Thanks to teacher and students of Eleven Senior High School, Surabaya and validator of pocketbook based Augmented Reality application, and those have contributed to this research.

\section{Declaration of Conflicting Interests}

The authors declared no potential conflicts of interest with respect to the research, authorship, and/or publication of this article.

\section{Funding}

The authors received no financial support for the research, authorship, and/or publication of this article.

\section{References}

Abdusselam, M.S., \& Karal, H. (2020). The effect of using augmented reality and sensing technology to teach magnetism in high school physics. Technology, Pedagogy and Education, 29(4), 407-424.

https://doi.org/10.1080/1475939X.2020.1766550

Adam, A.S., \& Suprapto, N. (2019). One-stop physics e-book package development for senior high school learning media. International Journal of Emerging Technologies in Learning, 14(19), 150-158. https://doi.org/10.3991/ijet.v14i19.10761

Ahmad, A.M., Goldiez, B.F., \& Hancock, P.A. (2005). Gender Differences in Navigation and Wayfinding using Mobile Augmented Reality. In Proceedings of the Human Factors and Ergonomics Society Annual Meeting. https://doi.org/10.1177/154193120504902111

Aljojo, N., Munshi, A., Zainol, A., Al-Amri, R., Al-Aqeel, A., Al-khaldi, M. et al. (2020). Lens application: mobile application using augmented reality. International Journal of Interactive Mobile Technologies, 14(2), 160-177. https://doi.org/10.3991/ijim.v14i02.11726

Arslan, R., Kofoğlu, M., \& Dargut, C. (2020). Development of augmented reality application for biology education. Journal of Turkish Science Education, 17(1), 62-72. https://doi.org/10.36681/tused.2020.13

Bakri, F., Permana, H., Wulandari, S., \& Muliyati. D. (2020). Student worksheet with AR videos: Physics learning media in laboratory for Senior High School students. Journal of Technology and Science Education, 10(2), 231-240. https://doi.org/10.3926/jotse.891

Chen, C.P. \& Wang, C.H. (2015). Employing augmented-reality-embedded instruction to disperse the imparities of individual differences in earth science learning. Journal of Science Education and Technology, 24, 835-847. https://doi.org/10.1007/s10956-015-9567-3

Crompton, H. (2013). A historical overview of mobile learning: Toward learner-centered education. In Handbook of mobile learning (3-14).

Díaz-Noguera, M.D., Hervas-Gomez, C., \& Calle, A.M. de la (2019). Professional action competences through experiences with augmented reality. Journal of Turkish Science Education, 16(4), 554-568.

https://doi.org/10.36681/tused.2020.7 
Dünser, A., Walker, L., Horner, H., \& Bentall, D. (2012). Creating interactive physics education books with augmented reality. In Proceedings of the 24th Australian computer-human interaction conference (107-114). https://doi.org/10.1145/2414536.2414554

Fidan, M., \& Tuncel, M. (2019). Integrating augmented reality into problem based learning: The effects on learning achievement and attitude in physics education. Computers \& Education, 142, 103635. https://doi.org/10.1016/j.compedu.2019.103635

Gunawan, G., Nisrina, N., Suranti, N.M.Y., Herayanti, L., \& Rahmatiah, R. (2018). Virtual laboratory to improve students' conceptual understanding in physics learning. Journal of Physics: Conference Series, 1108, 012049. https://doi.org/10.1088/1742-6596/1108/1/012049

Hake, R. (1998). Interactive engagement versus traditional methods: A six-thousand-student survey of mechanics test data for introductory physics courses. American Journal of Physics, 66(1), 64-74.

https://doi.org/10.1119/1.18809

Halliday, D.W., Resnick, R., \& Walker, J. (2013). Fundamentals of Physics Extended (10th ed.). John Wiley \& Sons.

Husnaini, S.J., \& Chen, S. (2019). Effects of guided inquiry virtual and physical laboratories on conceptual understanding, inquiry performance, scientific inquiry self-efficacy, and enjoyment. Physical Review Physics Education Research, 15(1). https://doi.org/10.1103/PhysRevPhysEducRes.15.010119

Hsu, T.C. (2019). Effects of gender and different augmented reality learning systems on English vocabulary learning of elementary school students. Universal Access in the Information Society, 18(2). https://doi.org/10.1007/s10209-017-0593-1

Ibáñez, M.B., Portillo, A.U., Cabada, R.Z., \& Barrón, M.L. (2019)Impact of augmented reality technology on academic achievement and motivation of students from public and private Mexican schools. A case study in a middle-school geometry course. Computers \& Education, 145, 103734.

https://doi.org/10.1016/j.compedu.2019.103734

Kustijono, R., \&. Hakim, S.R. (2014). Pengaruh intensitas cahaya dan jarak pada sistem Augmented Reality objek animasi. Jurnal Pendidikan Fisika dan Aplikasinya (JPFA), 4(2), 8-14.

https://doi.org/10.26740/jpfa.v4n2.p8-14

Lee, K. (2012). Augmented reality in education and training. TechTrends, 56(2), 13-21. https://doi.org/10.1007/s11528-012-0559-3

López-Belmonte, J., Pozo-Sánchez, S., Fuentes-Cabrera, A., \& Romero-Rodríguez, J.M. (2020). Uses and integration of augmented reality in the educational cooperatives of Andalusia (Spain). Journal of Technology and Science Education, 10(1), 4-16. https://doi.org/10.3926/jotse.622

Marneanu, I., Ebner, M., \& Rößler, T. (2014). Evaluation of augmented reality frameworks for android development. International Journal of Interactive Mobile Technologies, 8(4), 37-44.

https://dx.doi.org/10.3991/ijim.v8i4.3974

Mubarok, H., \& Aliyah, H. (2019). Islamic students understanding about the center of the earth in science and Islam perspective. Journal Intellectual Sufism Research, 2(1), 7-13. https://doi.org/10.52032/jisr.v2i1.40

Nandyansah, W., Suprapto, N., \& Mubarok, H. (2020). Picsar (physics augmented reality) as a learning media to practice abstract thinking skills in atomic model. Journal of Physics: Conference Series, 1491, 012049. https://dx.doi.org/10.1088/1742-6596/1491/1/012049

Permana, F., Tolle, H., Utaminingrum, F., \& Dermawi, R. (2019). Development of augmented reality (AR) based gamelan simulation with leap motion control. International Journal of Interactive Mobile Technologies, 13(12), 120-135. https:// doi.org/10.3991/ijim.v13i12.9270 
Prakoso, A.B., Adityas, H., Nurhaqi, M., \& Setianto (2019). Pemodelan gerak orbit planet secara komputasi menggunakan matlab. Jurnal Ilmu dan Inovasi Fisika, 3(1), 10-18. https://doi.org/10.24198/jiif.v3i1.20622

Radu, I., \& Schneider, B. (2019, May). What Can We Learn from Augmented Reality (AR)? Benefits and Drawbacks of AR for Inquiry-based Learning of Physics. In Proceedings of the 2019 CHI Conference on Human Factors in Computing Systems (1-12). https://doi.org/10.1145/3290605.3300774

Rohendi, D., \& Wihardi, Y. (2020). Learning three-dimensional shapes in geometry using mobile-based augmented reality. International Journal of Interactive Mobile Technologies, 14(09), 48-60.

https://doi.org/10.3991/ijim.v14i09.13035

Samuel J.L., Sanny, J., \& Moebs, W. (2018) University physics. Houston, Texas: OpenStax, Rice University.

Serway, R.A. (2018). Physics for scientists and engineers with modern physics. Cengage Learning.

Sing, A.L.L., Ibrahim, A.A.A., Weng, N.G., Hamzah, M., \& Yung, W.C. (2020). Design and development of multimedia and multimarker detection techniques in interactive augmented reality colouring book. Computational Science and Technology (605-616). https://doi.org/10.1007/978-981-15-0058-9_58

Sirakaya, M., \& Cakmak, E.K. (2018). Effects of Augmented Reality on Student Achievement and Self-Efficacy in Vocational Education and Training International. Journal for Research in Vocational Education and Training (IJRVET), 5(1), 1-18. https://doi.org/10.13152/IJRVET.5.1.1

Suprapto, N., \& Nandyansah, W. (2021). PicsAR: A Physics Visualisation to Enhance Students' Thinking Skills in Abstract Concepts. Journal of Physics: Conference Series, 1805, 012024.

https://doi.org/10.1088/1742-6596/1805/1/012024

Suprapto, N., Nandyansah, W., \& Mubarok, H. (2020). An evaluation of the "PicsAR" research project: An augmented reality in physics learning. International Journal of Emerging Technologies in Learning, 15(10), 113-125. https://doi.org/10.3991/ijet.v15i10.12703

Wang, W.C., \& Chyi-In, W. (2004). Gain score in item response theory as an effect size measure. Educational and psychological measurement, 64(5), 758-780. https://doi.org/10.1177/0013164404264118

Wayne, A. J., \& Youngs, P. (2003). Teacher characteristics and student achievement gains: A review. Review of Educational research, 73(1), 89-122. https://doi.org/10.3102/00346543073001089

Published by OmniaScience (www.omniascience.com)

Journal of Technology and Science Education, 2021 (www.jotse.org)

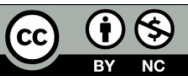

Article's contents are provided on an Attribution-Non Commercial 4.0 Creative commons International License. Readers are allowed to copy, distribute and communicate article's contents, provided the author's and JOTSE journal's names are included. It must not be used for commercial purposes. To see the complete licence contents, please visit https://creativecommons.org/licenses/by-nc/4.0/. 